\title{
SCHOOLING AND ACHIEVEMENT: A STUDY OF PERUVIAN CHILDREN
}

\author{
HAROLD W. STEVENSON and CHUANSHENG CHEN
}

University of Michigan, Ann Arbor, MI 48109, U.S.A.

\begin{abstract}
This study explores the effect of attending school on children's achievement in reading and mathematics and on a test of general information. The major focus was on the interaction between three variables: children's age [young (6-8 years) or old (9-12)], location (city slums or rural villages in the highland or jungle areas of Peru), and the number of years of schooling (none, 1, 2, or 3 years). A follow-up study was conducted nine years after the original testing. Schooling had a positive effect on children's performance, but the degree of influence depended upon all three of the major variables. Schooling tended to have a greater effect on the achievement scores than on the general information scores. In general, scores were highest among children residing in the city and lowest among children living in the remote jungle areas. After controlling for location, age, and years of education, family variables such as parental education and home quality had a small, but significant influence on children's knowledge of reading, mathematics, and general information.
\end{abstract}

\section{Introduction}

There rarely is an opportunity in industrialized countries to compare the performance of children of the same age who do and do not attend school. Although there is a large literature on the effects of schooling on academic achievement in industrialized and developing countries, the studies typically are concerned with such variables as the availability of textbooks, class size, and teachers' salaries (e.g., Fuller, 1987); the quality of the school (e.g., Heyneman \& Loxley, 1983); the influence of extending the length of the school year (e.g., Heyns, 1978); or the analysis of formal schooling as a means of imparting knowledge (e.g., Anderson, Spiro, \& Montague, 1977). Opportunities to evaluate what nonschooled children learn about academic subjects in their everyday environments do exist, however, in countries where there is not universal schooling of young children.

It seems obvious that schooling should have a positive effect on academic achievement.

\footnotetext{
The original study was supported by a grant from the W. T. Grant Foundation and the National Science Foundation; the follow-up study was supported by a small grant from the Social Science Research Council. We are indebted to many people who participated in this project, especially Beatrice Bonnevaux, Alexander Wilkinson, Timothy Parker, Teofilo Altamirano, Max Gonzalez, David Uttal, and William Bacon. We wish to thank the examiners, research assistants, parents, and the children for their contribution to this research.
} 
Such an assumption is broadly accepted and forms the rationale for the widespread growth of schooling across the world. But there are other, more interesting relations between schooling and achievement that need to be explored. For example, does attending school have similar effects at all ages and for children of different cultural and economic backgrounds? Would the rate of acquiring the first-grade curriculum by children who enter school at the age of nine differ from that of children who enter school at the age of six or seven? Would the effects differ, depending upon whether the children live in the city or in rural areas? Do non-schooled children who live in the city and have access to products of technology, such as television, movies, newspapers, and magazines, possess notably greater academic skill and knowledge than do nonschooled children who reside in rural areas where access to such sources of information is more limited?

A second category of question is whether schooling contributes more strongly to children's progress in one area than in another. For example, is there a greater difference between schooled and nonschooled children in reading than in mathematics? Do nonschooled children acquire knowledge that is potentially available in everyday settings as readily as schooled children? Goodnow (1969) proposed that tasks most vulnerable to the effects of schooling are ones dependent upon words, drawing, and visual imagery. If this is correct, reading should be more strongly influenced by schooling than mathematics. However, we have little idea of what school-age children learn about reading without formal instruction. In mathematics, there is evidence that some children, especially those engaged in activities such as street vending, demonstrate remarkable skill in handling basic mathematical operations, even though they have not been taught mathematics formally (e.g., Carraher, Carraher, \& Schliemann, 1985; Saxe, 1988). We are unable to find any studies of how attending school influences the acquisition of common knowledge in a culture. Whether the strategies learned in school generalize to the acquisition of information outside of school is, however, a question of special interest. We seek in this study, therefore, to compare the performance of schooled and nonschooled children in three areas: reading, mathematics, and general information.

\section{Background Information}

We chose Peru as the locale for our study. Although all children in Peru are expected to attend elementary school, at the time of our study only $53 \%$ entered school at the appropriate age of six years. National statistics showed that by the time children were nine years old, $78 \%$ were enrolled in school. In subsequent years of school, however, enrollment declined. These statistics combine data for the two major ethnic groups in Peru, the Mestizos (mixed Indian and Spanish) and the indigenous Quechua-speaking Indians. It seemed likely that the percentage of Quechua children enrolled in school was below these national figures. Because of this, and because of our interest in maximizing our opportunities for studying children who had not attended school, we chose the Quechua as subjects for our research.

Schools in Peru are generally very poorly equipped. For example, according to the latest available statistics, the value of the classroom materials and other nonsalary items in Peruvian schools is approximately $\$ 3$ per pupil (Heyneman, 1984). In the United States, the expenditure for these items was approximately $\$ 220$ per pupil. Because the Quechua are among the poorest citizens of Peru, it is likely that the average expenditure per pupil 
was well below the national average. For example, in Lamas, one of our research sites, not every classroom had a blackboard, few had maps or pictures, and textbooks were not available for every child. In short, we investigated the effects of schooling under conditions that typically consisted of little more than a teacher who imparted information and skills with the benefit of few of the materials that teachers in developed nations would consider essential for their task.

Three locations were chosen for the study, one urban and two rural. They are described briefly in the following paragraphs.

Lima. In the barren hills in the outskirts of Lima, millions of persons live in squatter settlements, called barriadas or pueblos jovenes. The inhabitants of these settlements, primarily Quechua peasants who have migrated from the highlands of Peru, live under very difficult conditions. Near the highway, communities are relatively stable; as one climbs the hills, the conditions of the homes become more flimsy, the population becomes more transient, and the living facilities become more primitive. The families left the highlands for many reasons: to find work, to find a 'better life', to study or for their children to study, or for adventure. Most migrants stay in the city once they have moved, but remain in close contact with their relatives and friends in the highlands. The barriadas in which we conducted our research were settled by indigenous families who migrated primarily from the highland villages in the region of Andahuaylas. In the barriadas, schools are better equipped than those in the rural areas, but are often housed in stark buildings with broken windows, well worn desks and equipment, and empty play yards. Families in the barriadas are very poor, but nevertheless have more material possessions, such as radios, machines, and books, than do families in the rural areas.

Andahuaylas. One of two rural groups resided in Andahuaylas, an important area in the Inca empire. The inclusion of the highland children made it possible to compare children from the same cultural group, some of whom remained in their homeland and some of whom resided in the city. Highlands families retain traditional cultural values and the Quechua language, while children whose families have migrated to Lima must adapt to the Mestizo culture of the city and to the use of Spanish as the daily language outside the home.

Lamas. Our second rural group consisted of Quechua children who live in villages in the area of Lamas, which is located in the selva, or rain forest of mid-Northern Peru. This is one of the most remote areas of the country. During the rainy season access to many of the villages is impossible. The families we studied were descendants of the Chancas, a Quechua-speaking group residing in Andahuaylas that was defeated in a battle with the Incas 500 years ago. After their defeat, they left the highlands and settled many hundreds of miles northeast of Andaluaylas in the foothills of the Andes. Members of the group did not become assimilated into other indigenous Amazonian groups, but retained their Quechua language and remnants of their highland culture. Mestizos dominate the culture and economy of the selva. Thus, the Quechua of the selva, like those who migrated to the city, are faced with the task of adapting to the Mestizo culture and to the use of Spanish as the language for commerce and interaction outside their own group.

\section{Method}

Subjects

We chose to work with children at two age levels: $6-8$ year olds (young group) who either 
had never attended school or who were enrolled in first grade, and 9-12 year olds (old group) who had never attended school or who were attending first, second, or third grade.

Our sample consisted of 1151 children: 387 from Lima, 428 from Andahuaylas, and 336 from Lamas. Among these, $51 \%$ were girls. The schooled children attended 18 different schools in Lima, 17 in Andahuaylas, and 16 in Lamas. We included all the schools we could find in each location. The staffs of the school were very cooperative, both because of their interest in the study and because we had the approval and support of governmental authorities for conducting the research.

Locating children who did not attend school was more difficult than finding children who did attend school. However, even among the nonschooled children, we were able to obtain excellent cooperation. Our procedure was to send a person to the neighborhoods or villages to seek families with a child of the proper age. We had practically no loss of subjects once testing began. Few of the children in any of the locations had books or toys, and expressed great interest in being able to 'play' with the test materials in the presence of an attentive and responsive adult.

Nine years on the average after we completed the original study we conducted a followup study. We revisited each of the research sites and attempted to locate the subjects who had participated in the original testing. The impoverished economy of Peru has led to increased mobility, and individuals have found it necessary to move from one place to another in search of employment. Migration from the highlands to the city has increased and there also has been an increase in migration within regions of the selva, where lucrative jobs have become available because of the cocaine trade. We were able to interview and test approximately one-third of the original subjects: 141 in Lima, 165 in Andahuaylas, and 89 in Lamas. Figure 4.1 presents the information we obtained about the current status of the original sample. We obtained this information from the subjects, their parents, or others in the neighborhoods or villages. Andahuaylas was the most stable community in the sense that all but $9 \%$ of the children could be accounted for; Lima was least stable, for information could not be obtained concerning $31 \%$ of the children.

A critical question in follow-up studies is whether the follow-up subjects are representative of the original sample. To evaluate this possibility, we compared the three original test scores: reading, mathematics, and general information. When the test scores obtained by the follow-up subjects were compared to those of the individuals we were unable to locate, neither the difference in scores for mathematics or for general information was significant, $p \mathrm{~s}>.05$. For reading, the follow-up sample received slightly

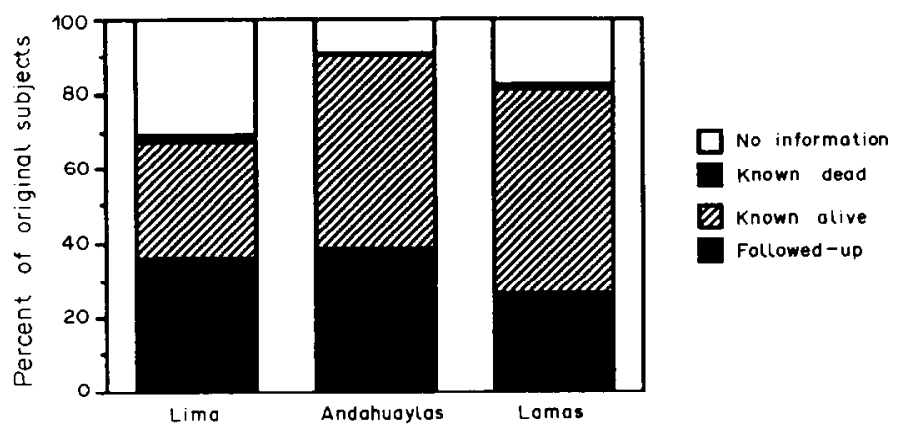

Figure 4.1. The outcome nine years later for the original subjects. 
higher scores than the remainder of the subjects (means $=25.9$ vs. 25.1$), F(1,1094)=4.65$, $p<.05$. In addition, there was not a significant difference between members of the subsample and the remaining subjects for two indices we had of socioeconomic status: educational level of the parents and the quality of the household (to be described later), $p s>.05$. The proportions of males and females were comparable in the original and follow-up samples: $49 \%$ of the follow-up sample and $51 \%$ of the original sample were female. On the basis of these data it is difficult to accept the hypothesis that the subsample was unrepresentative of the total sample.

\section{Measures of Achievement}

There were no standardized achievement tests for reading and mathematics in Peru, thus we devised our own. The tests were constructed after reviewing textbooks used in Peruvian schools and discussing the items with Peruvian colleagues. The language of instruction in Peruvian schools is Spanish. Even though efforts have been made to provide instruction in Quechua in the highlands, such instruction is a very rare phenomenon. The reading test, therefore, was written in Spanish. The test consisted of the following sections: reading letters and words, selecting a picture described by a word, and reading comprehension. There was a total of 49 items. The mathematics test included 30 items that involved counting, the concept of more and less, reading numbers, oral word problems, and written computation problems. The reliability (Cronbach alpha) of the reading test was .94 and of the mathematics test, .91 .

The general information test contained questions whose answers are not directly taught in school but are part of common knowledge, including simple ones such as how many paws a dog has to more complicated ones, such as the color of the Peruvian flag, things a plant needs in order to grow, and why people cannot live under water. For each of the 14 questions, a score of 2 was given to each correct answer and 1 to any partially correct answer. The coding scheme was developed after review of the types of answers given by the children. The reliability (Cronbach alpha) of the general information test was .71.

The tests started with easy questions and became more difficult. Testing contined until the child made errors on either three or four consecutive questions, depending upon the test. All tests were administered by examiners (substitute teachers or college students) fluent in the child's first language (either Ouechua or Spanish). Nearly every child in Lima was tested in Spanish; more than $75 \%$ of the children in Andahuaylas were tested in Quechua. In Lamas, the language of testing tended to depend upon the child's status in regard to schooling: nearly all of the children who attended school were tested in Spanish, but approximately half of the children who did not attend school were tested in Quechua.

The versions of the tests used in the follow-up study were constructed by adding more difficult items at the end of the test. Even so, the most difficult items were at no higher than the fifth grade level. The most difficult reading items included sentences such as, "Se prohibe llevar comida fuera de la zona del puesto de refrescos", ("Taking food outside the area of the refreshment stand is prohibited."). After reading the sentences, the subject answered questions about the sentences. The most difficult mathematics items were ones such as $1 / 5+3 / 4$ and $.08 \times 10$. The number of points possible in the adult versions of the tests was increased from 49 to 60 in reading, 30 to 51 in mathematics, and 28 to 40 in general information. 


\section{Interviews}

An interviewer visited the home of each child. In the original study, we were able to conduct 1025 interviews, nearly all with the child's mother or father. The relevant aspects of the interview here are those dealing with the child's family background and home life.

In the follow-up study, each of the subjects that could be found was interviewed about his or her educational history and other matters. On the basis of these interviews, we found that schooling had not ended for many of the subjects at the time of our original study. The follow-up subjects in Lima had attained an average of 7.0 years of education ( $\mathrm{SD}=3.3$ ), in Andahuaylas, 3.6 years $(\mathrm{SD}=1.9)$, and in Lamas, 5.3 years $(\mathrm{SD}=1.5)$. These are notably higher than the educational levels attained by the subjects' fathers: 4.9 years in Lima, 2.7 years in Andahuaylas, and 1.9 years in Lamas. The subjects' mothers had even lower levels of education: 2.2 years in Lima, 0.7 in Andahuaylas, and 0.1 in Lamas. The biggest increases between the two generations, therefore, were for the families who had migrated to the city and among the residents of the selva. The latter change is likely to be due to the improvement of the economy of the selva during the past decade. Within each location, the number of years the individuals attended school was unrelated to the educational level of their fathers or mothers; the $r$ s ranged from -.07 to .14 , all $p s>.05$.

\section{Results and Discussion}

Before describing the results in detail, it is useful to summarize the major findings. Two analyses were performed separately for each of the tests, one comparing the effects of age (6-8 vs. 9-12 year-olds) and schooling (no school vs. first grade) and the second comparing the effects of the amount of schooling (no schooling, first, second, and third grade) for the 9-12 year-olds. In general, children who attended school did better on all three of the tests than did nonschooled children, and the longer children were in school, the higher were their scores. The effects of schooling were more striking for mathematics and reading, subjects that are taught in school, than for general information, which is not directly taught in school. The effects depended, however, upon location and the child's age. In addition to age and schooling, family variables made a small, but significant contribution to the prediction of children's test scores.

\section{Original Testing}

\section{Mathematics}

The mathematics scores of the nonschooled and first-grade children are presented in the left pancl of Figure 4.2. Several features are immediately evident. Both the younger and older children residing in Lima had learned a great deal about the rudiments of mathematics from their daily activities outside of school. This is due, in part, to the fact that children play a role in the economy of families residing in the barriadas. From a young age, children participate in commercial activities that require calculation, such as selling foodstuffs, personal items, and glass they have collected. Attendance at first grade produced a modest improvement in their mathematics scores. Much greater effects of schooling were evident in the scores of the children in Andahuaylas. In Andahuaylas, age 


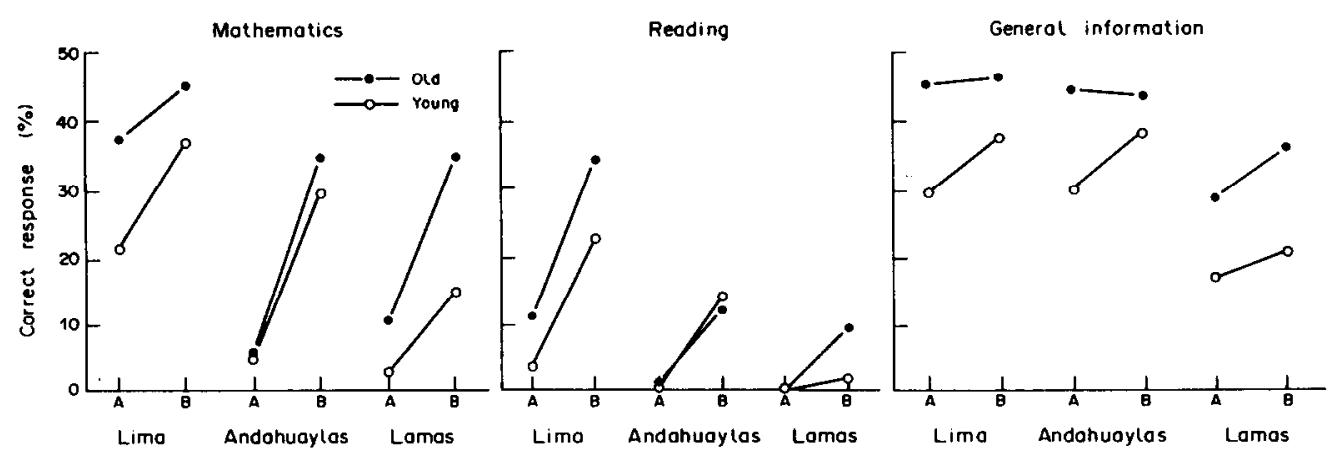

Figure 4.2. The percentage of correct response for nonschooled and first grade subjects in the three locations. A $=$ No school; $\mathrm{B}=$ Grade 1 .

was not a significant factor in influencing children's knowledge of mathematics among the nonschooled children; neither the younger nor the older group could do more than count a few numbers. Improvement was rapid, however, among the Andahuaylas first graders. In Lamas, the older children showed a large gain from their first year of education, but the young Lamas children showed only moderate benefit from attending school.

The rate of improvement of children in Lima and Andahuaylas remained relatively constant through the second and third grades, but that of Lamas children decreased after the first grade in school (see Figure 4.3, mathematics panel). Overall, the highest scores made during the three years of school occurred in Lima and the lowest in Lamas.

In the preceding comparisons of nonschooled and first grade children, significant main effects were found for educational status, $F \mathrm{~s}(1,194-274)=34.22-187.39$, $p$ s $<.001$. Age effects were significant only in Lima and Lamas, $F_{\mathrm{s}}(1,253-194)=31.58,110.17$, $p$ s $<.001$. The interaction between age and schooling was not significant in Lima or Andahuaylas, but was significant in Lamas, $F(1,194)=21.81, p<.001$. This interaction reflects a similar effect of schooling on the younger and older children in Lima and Andahuaylas, and a greater effect on the older than on the younger children in Lamas. For the comparisons of older subjects who received varying amounts of schooling, significant main effects were found for grade level, $F(3,709)=273.27, p<.001$, for location, $F(2,709)=133.69, p<$ .001 , and for the interaction between grade level and location, $F(6,709)=10.45, p<.001$.

\section{Reading}

The results for the reading test are presented in the middle panel of Figure 4.2 for the
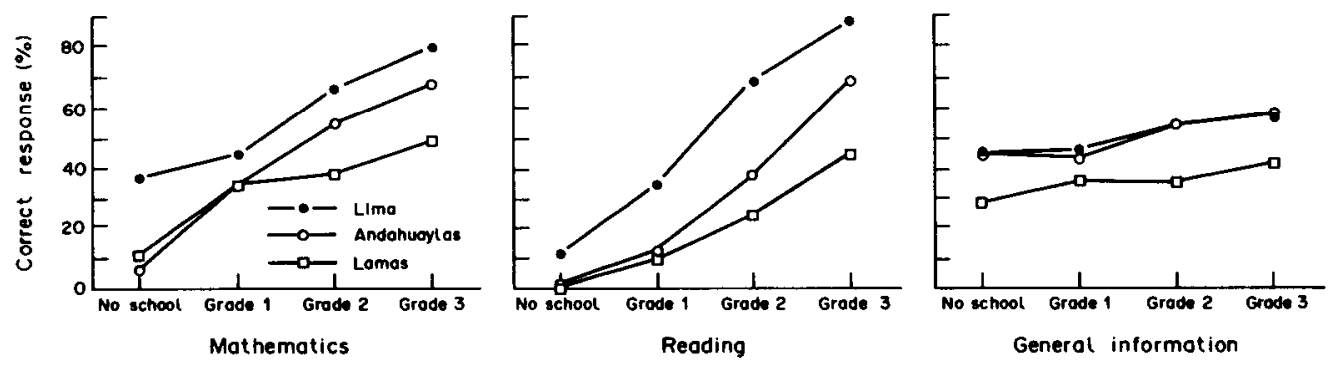

Figure 4.3. The percentage of correct response for older subjects with varying levels of schooling. 
young and old groups that did and did not attend first grade. It is evident that nonschooled children in Lamas and Andahuaylas remained illiterate, regardless of their age. In I ima, the older children did learn something about the alphabet and simple words even though they did not attend school.

Scores of first graders exceeded those of the nonschooled children, Fs $(1,187-269)=$ 36.14-62.81, $p \mathrm{~s}<.001$, and scores of the older children were higher than those of the younger children in Lima and Lamas, $F_{\mathrm{S}}(1,250,187)=12.84,22.47, p \mathrm{~s}<.001$. Schooling did not have equivalent effects in all locations and for both age groups. In Lima and Andahuaylas, the reading scores of young children benefited just as much from attending school as those of the older children. In Lamas, however, most of the young children remained illiterate, even though they attended school, while older children gained some skill in reading from attending the first grade. The interaction term between age and schooling was significant for Lamas, $F(1,187)=24.74, p<.001$.

Reading scores for the older children who attended school from one to three years are presented in Figure 4.3. Reading skill improved with each year of schooling. The patterns for Lima and Andahuaylas were very similar, although the scores of the Andahuaylas children were approximately one year behind those of the Lima children at each level of schooling. This is undoubtedly related to the fact that Andahuaylas children were less familiar with Spanish than were the Lima children. Progress was smaller by children in Lamas during each successive year of schooling than in the other two locations. Analysis of variance revealed a highly significant effect of grade level, $F(2.698)=178.58, p<.001$, of location, $F(2,698)=78.55, p<.001$, and of the interaction between these two variables, $F(6,698)=4.73, p<.001$.

\section{General Information}

Children's scores on the general information test were remarkably similar in Lima and Andahuaylas (see Figure 4.2). The analysis of variance for children who did and did not attend first grade revealed a significant effect of schooling in all three locations, $F \mathrm{~s}(1,195$ $274)=6.71-8.66, p \mathrm{~s}<.05$, and of age, $F \mathrm{~s}(1,195-274)=45.44-55.71, p \mathrm{~s}<.001$. The interaction between location and age was significant in Lima and Andahuaylas, $F \mathrm{~s}$ $(1,254,274)=4.21-10.23, p s<.05$, but not in Lamas. This interaction is derived from the fact that the scores of both the younger and older groups in Lamas benefited from schooling, while in Lima and Andahuaylas only the scores of the younger children attending school improved.

As is shown in Figure 4.3, there was a small increase in the scores on general information for the older children who attended second and third grades, $F(3,711)=37.30, p<.001$. The increase was much smaller than it was for either reading or mathematics. The average scores for children in Lima and Andahuaylas were nearly identical at all levels of schooling, and were consistently higher than those in Lamas, $F(2,711)=103.91, p<.001$. These data suggest that there is a more modest effect of schooling on children's acquisition of general information, which is not directly taught in school, than there is for the two core subjects of elementary school, reading and mathematics. Indeed, there was no improvement at all in the general information scores of older children in Lima and Andahuaylas as a result of being in the first grade of school.

\section{Relation Among Tests}

Scores in mathematics and reading were significantly interrelated, $r s=.31$ to $.71, p s<$ 
.05 , except in Lamas, where the nonschooled children were illiterate. For the schooled children, the corrclation between scores on general information and mathematics and reading tests was significant for 19 of the 24 possible correlations, $r \mathrm{~s}=.26$ to $.53, p \mathrm{~s}<.05$. Correlations for the nonschooled children were significant only in Lima: the correlation between general information and mathematics was .52 (young group) and .65 (old group), $p s<.001$. The correlation between general information and reading was .14 (young group), $p>.05$, and .36 (old group),$p<.01$.

\section{Follow-Up Testing}

Scores in mathematics, reading, and general information had improved by the time of the follow-up testing, as is evident in Figure 4.4. This figurc presents the means for the items that appeared in both the original and follow-up testing. All of the increases were significant, $t \mathrm{~s}(51-140)=4.1$ to $19.1, p \mathrm{~s}<.001$. Children in Lamas made the greatest gains in test scores over the nine-year period, which may be accounted for by the fact that they also showed the greatest increase in the years of education of the children in the three locations. In comparison to the reading and mathematics scores, there was less improvement in the subjects' scores on the general information test between original and follow-up testing.

When all of the items in the follow-up test are considered, there was not a significant difference in the average scores among the three locations for reading, $p>.05$. The mean percentage of correct responses ranged between $77 \%$ and $83 \%$. There were significant location differences for the follow-up tests of mathematics and general information. The percentages of correct response for mathematics were $68 \%$ (Lima), 52\% (Andahuaylas), and $60 \%$ (Lamas), $F(2,310)=22.09, p<.001$; and for general information, the corresponding percentages were $57 \%, 44 \%$, and $43 \%, F(2,310)=22.09, p<.001$.

The scores obtained by the subjects on the first testing were not predictive of the scores they received on the second testing in either Andahuaylas or Lamas, $r s-.09$ to .15 . In Lima, however, the correlations were significant: .26 for reading, .38 for mathematics, and .26 for general information, all $p s<.01$. It is difficult to understand why these differences in the degrec of relation between first and second testing should have occurred among the three locations. They are not due to a statistical artifact resulting from differences among the locations in the variability of scores. For example, the standard deviations of the mathematics scores on original testing and follow-up testing were 16 and 25 for Lima, 17

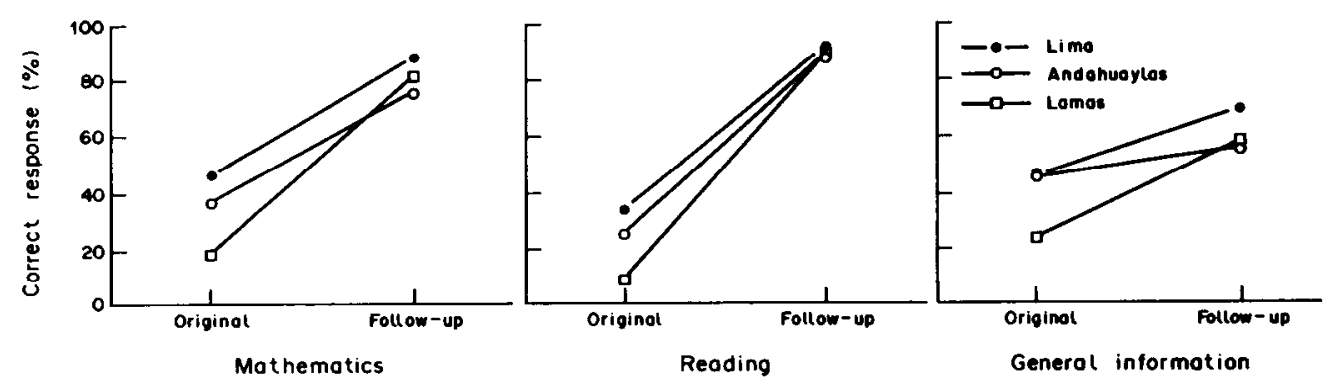

Figure 4.4. The percentage of correct response for the original and follow-up subjects on the test items common to the original and follow-up tests. 
and 29 for Andahuaylas, and 19 and 20 for Lamas. Rather, the differences appear to be due to greater opportunities provided to children in the city to continue their education and to maintain or to continue to develop their academic knowledge. Able children are more likely to have the opportunity in a city to continue in school, whereas in remote rural areas access to more than few years of education is much more unpredictable. In addition, city dwellers who are capable of reading have access to books; those who know some mathematics are more likely to find themselves in situations where mathematics can be used. It appears, therefore, that when opportunities for continued learning are accessible, there is a stabilizing of individual differences in academic skills.

\section{Correlations with Years of Schooling}

The total number of years of schooling was significantly related to the scores on the follow-up tests. In Lima, the correlations were .68 (mathematics), .58 (reading), and .54 (general information). The corresponding correlations in Andahuaylas were .66, .71, and .60 ; and in Lamas, they were $.55, .72$, and .52 .

\section{Other Correlates of Achievement}

Whether or not a child goes to school, the age the child enters school, and the number of years the child attends school are related to a vast array of other variables. As has been pointed out repeatedly (e.g., Rogoff, 1981), parents of children who attend school may be better educated than parents who keep their children at home, they may value education more highly, may be better off financially and able to purchase such items as books and radios, and they may be more likely to provide extra tutoring at home on school-related tasks. We assessed the contribution of each of these variables to the prediction of children's scores during the original testing by means of stepwise regression analyses. The entries included location, grade level, age, mid-parental education, quality of the home (i.e., presence of electricity, any machine, newspapers or magazines, radio, television, books, children's books, toys, pictures, and portraits), and parental involvement in teaching (i.e., efforts to teach the child about colors, numbers, letters, money, the seasons, riddles, Spanish, and games; reading to the child and telling stories to the child).

The regression analysis for each of the tests is summarized in Table 4.1. The variables included in these equations accounted for a remarkably large percentage of the variability in mathematics scores $(68 \%)$, and large percentages of the variance in reading and general information scores $(52 \%$ and $48 \%$, respectively). It is evident that the variable contributing most strongly to these effects was educational status. parental education and home quality made small, but significant contributions $(0.6$ to $1.1 \%)$ to the total variances. The degree of effort parents made to teach their child had a significant influence only in Lima.

Regression analyses were also conducted for the results of the follow-up tests. The variables entered into these analyses were location, total years of education, and current home quality. The major effects for all three tests were derived from total years of education. After controlling for location, years of education accounted for $33 \%$ of the variance in mathematics, $36 \%$ in reading, and $24 \%$ in general information. Home quality accounted for an additional $1 \%$ of the total variance, $p \mathrm{~s}<.05$. 
Table 4.1

Stepwise Regression Analyses

\begin{tabular}{|c|c|c|c|c|c|c|}
\hline & \multicolumn{2}{|c|}{ Mathematics } & \multicolumn{2}{|c|}{ Reading } & \multicolumn{2}{|c|}{ General information } \\
\hline & $\mathrm{R}^{2}$ & $\begin{array}{c}\text { cumulative } \\
\mathrm{R}^{2}\end{array}$ & $\mathrm{R}^{2}$ & $\underset{R^{2}}{\text { cumulative }}$ & $\mathrm{R}^{2}$ & $\underset{R^{2}}{\text { cumulative }}$ \\
\hline \multicolumn{7}{|l|}{ Step } \\
\hline 0 Location & .103 & .103 & .065 & .065 & .178 & .178 \\
\hline 1 Grade level & .545 & .648 & .434 & .499 & .225 & .403 \\
\hline 2 Age & .014 & .662 & .004 & .503 & .067 & .470 \\
\hline 3 Parental education & .004 & .666 & .007 & .510 & .003 & .473 \\
\hline 4 Home quality & .006 & .672 & .004 & .515 & .003 & .476 \\
\hline 5 Parent teaching & .004 & .676 & $.0001^{*}$ & .515 & $.001^{*}$ & .477 \\
\hline $\mathrm{N}$ & & 952 & & 936 & & 952 \\
\hline
\end{tabular}

Note: - All the $\mathrm{R}^{2}$ are significant at .05 level or above, except for the two marked with an asterisk.

\section{Conclusions}

The possibility of improving children's opportunities for education is a common reason parents give for migrating from the countryside to large urban centers. The data from this study support the rationality of this argument. Despite the extremely impoverished conditions that exist in the barriadas of Lima, children clearly benefited from the city environment. They demonstrated higher levels of academic achievement than the children in the rural areas in both reading and mathematics, whether or not they went to school. The benefit did not extend to their acquisition of general information; Lima children possessed no more information derived from their daily experiences than did the children in the rural villages of Andahuaylas. Both groups of children had a greater fund of common knowledge, however, than did the children in the remote villages of Lamas.

The relation between the age children entered school and their academic achievement was complex. Older children who attended school in the city obtained the highest scores of all the groups in both reading and mathematics. But the mathematics scores of older, nonschooled children in the city also were high. The nonschooled city children had learned much more from their daily experiences about mathematics than they had about reading, a finding that could be anticipated from the results of Carraher, Carraher, and Schliemann (1985) and Saxe (1988). In terms of differences between the mathematics scores of schooled and nonschooled children, the smallest difference occurred for the older city children. This was not because of a ceiling effect; less than half of the items were answered correctly. The opposite occurred with reading. Both schooled and nonschooled city children showed a greater benefit from instruction in reading than did the children in Andahuaylas and Lamas. In Andahuaylas, age had only a minimal effect on both reading and mathematics scores. All of the effects were attenuated for the general information test, where every group had acquired only modest amounts of knowledge about common objects, actions, and events.

As expected, years of schooling had a strong effect on academic achievement. After controlling for location, this variable made the strongest contribution to the prediction of the children's level of academic achievement. This was the case when the individuals were children between the ages of 9 and 12 , and when they were young adults between the ages 
of 18 and 21 . Family variables exerted a significant influence on the achievement test scores, but an effect that was vastly weaker than the child's total years of schooling.

Surprisingly, in the nine years after the original testing, the greatest improvement in scores occurred in Lamas. These subjects had received the lowest scores during the original testing, but, apparently due to the change in the economy of the region, children attended school longer and showed the greatest benefit from attending school than would have been anticipated on the basis of the children's earlier performance. Generally, scores improved greatly for both mathematics and reading between the original and follow-up testing. Scores on the general information test showed modest improvement in both Lima and Lamas, but in Andahuaylas, the subjects in the follow-up study were able to answer only one or two questions more than they had nine years earlier.

In reviewing these results, it is easy to forget the difficult, impoverished conditions under which these children live and were taught. Many were malnourished and possessed no clothing other than their school uniform. The teachers often had no more than high school education. Nevertheless, schooling had a profound effect on their academic achievement. Under more optimal circumstances it seems likely that they would make even more remarkable progress in acquiring the formal knowledge that is imparted in school.

\section{References}

Anderson, R. C., Spiro, R. J., \& Montague, W. F. (Eds.) (1977). Schooling and the acquisition of knowledge. Hillsdale, NJ: Erlbaum.

Barber, B. (1988). The influence of family demographics and parental teaching practices on Peruvian children's academic achievement. Human Development, 31, 370-377.

Carraher, T. N., Carraher, D., Schliemann, A. D. (1985). Mathematics in the streets and in schools. British Journal of Developmental Psychology, 3, 21-29.

Fuller, B. (1987). What school factors raise achievement in the Third World? Review of Educational Research, $57,255-292$.

Goodnow, J. J. (1969). Problems in research on culture and thought. In D. Elkind \& J. Flavell (Eds.), Studies in cognitive development. New York: Oxford University Press.

Heyneman, S. (1984). Two thirds of the world's students: Intellectual development and schoois in developing countries. Talk given at the Center for Advanced Study in the Behavioral Sciences, Stanford, CA.

Heyneman, S., \& Loxley, W. A. (1983). The effect of primary school quality on academic achievement across twenty-nine high and low income countries. American Joumal of Sociology, 88, $1162-1194$.

Heyns, B. (1978) Summer learning and the effects of schooling. New York: Academic Press.

Rogoff, B. (1981). Schooling and the development of cognitive skills. In H. C. Triandis \& A. Heron (Eds.). Handbook of cross-cultural psychology (Vol. 4, pp. 233-294). Boston: Allyn and Bacon.

Saxe, G. B. (1988). The mathematics of street vendors. Child Development, 59, 1415-1425. 